Adolfo Bronstein, Thomas Lempert

\section{Dizziness: A Practical Approach to Diagnosis and Management}

\section{Cambridge Clinical Guides}

Cambridge University Press, Cambridge 2007

238 pp., CD-ROM; GBP 35.00/USD 75.00

ISBN 978-0-521-83791-0

The first edition of this 200-page book with a video CD certainly serves as a very welcome and highly reliable guide for the clinician confronting the difficult and broad field of dizziness. The vestibular system is complex and therefore often needs indepth knowledge of several complicated structures, important nuclei, neuronal pathways, and networks. The organization of the book into eight chapters, augmented by tables and video clips, directly addresses the many questions of the clinician. The first two chapters introduce the reader step by step to the 'Essential Anatomy and Functions of the Balance System', the 'Symptoms and Examination of the Patient with Vertigo and Dizziness', before the next five deal with the differential aspects of five typical dizziness conditions (1. A Single Episode of Prolonged Vertigo, 2. Recurrent Vertigo and Dizziness, 3. Positional Vertigo, 4. Chronic Dizziness and Unsteadiness, and 5. Dizziness and Falls in the Elderly). For each condition the authors present the most important diseases, explaining the specific disorder, describing its clinical features, and elucidating pathophysiology, pertinent investigations, differential diagnosis, and principles of treatment. Furthermore, for those who have still not discovered a diagnosis for their own patient, the part entitled 'What to Do if You Don't Have a Clue' gives fruitful advice. Finally, a chapter on the different forms of treatment rounds off the book. Each chapter is clearly structured and illustrated with figures, schematic drawings, and tables.

As the title indicates, this book takes an, above all, practical approach to the diagnosis and treatment of different vertigo/dizziness syndromes. Practicing clinicians can quickly acquire an understanding of the physiological essentials of the vestibular system. The book is clearly written and adequately illustrated. However, its one shortcoming is the reference section: only a few books and relevant articles listed for further reading at the end of the book. The list gives an overview, but does not really help if one wants to delve into specific questions or diagnostic problems. Nevertheless, this is a thoroughly readable and highly recommendable book.

Marianne Dieterich, München
Thomas T. Warner and Susan B. Bressman (eds.)

\author{
Clinical Diagnosis and Management of Dystonia \\ Informa Healthcare, London 2007 \\ 280 pp.; GBP 75.00 \\ ISBN 978-1-84184-317-9
}

The book is a comprehensive update on dystonia. Numerous international experts in the field of movement disorders have contributed their original papers, elucidating the many clinical and scientific achievements realized during the last 30 years.

The first part of the book provides an overview of clinical signs and symptoms, the epidemiology, genetic forms and the pathophysiology of dystonia incorporating recent novel functional neuroimaging and electrophysiological findings. For the clinical diagnosis of the different forms of dystonia, many tables provide a summary of the different classifications currently in use based on the different etiologies.

In the second part of the book updated information is given upon the most frequent forms of dystonias, following the recent classification proposed by movement disorder specialists, i.e. primary generalized dystonia (DYT1 and others), primary focal dystonia (cervical, cranial, task-specific and laryngeal), dystoniaplus syndrome, secondary dystonia, tardive dystonia, paroxysmal dystonia and psychogenic dystonia.

In the third part of the book, the latest developments in medical and surgical treatments proposed to manage dystonia are summarized. A specific chapter is devoted to botulinum toxin injections. Further information on complementary treatments such as 'psychotherapy' would have been of value. The different specific rehabilitation programs for cervical dystonia and writing cramp are described in chapter 20 , which is useful for all the therapists interested in movement disorders. The chapter devoted to the role of a specialist dystonia nurse is particularly interesting regarding the clues to improved care of patients suffering from dystonia, although application of this care management depends on the health care systems and health care professions involved. At the end of the book, all the dystonia rating scales and qualityof-life scales available are presented in a critical manner, thus constituting a useful tool for clinicians and scientists. In most chapters, information is also presented in tables, balancing for the lack of illustrations. However, the numerous contributions to the 23 chapters by the different researchers will inadvertently result in some repetition, but this is not a limitation of the book if it is used as a research tool for one specific form of dystonia.

This reference book should be recommended to young neurologists or young neuroscientists interested in dystonia looking for updated knowledge in this field.

Marion Simonetta-Moreau, Toulouse Olivier Rascol, Toulouse

\section{KARGER}

(ㄷ) 2009 S. Karger AG, Basel

Fax +41 613061234 E-Mail karger@karger.ch www.karger.com www.karger.com/ene 